Review Article

\title{
Emerging and re-emerging infections: threat to the world
}

\author{
Harish Veerapalli* \\ Department of Global Health, University of South Florida, Florida, USA \\ Received: 10 December 2019 \\ Accepted: 16 January 2020 \\ *Correspondence: \\ Dr. Harish Veerapalli, \\ E-mail: drharishv84@gmail.com \\ Copyright: () the author(s), publisher and licensee Medip Academy. This is an open-access article distributed under \\ the terms of the Creative Commons Attribution Non-Commercial License, which permits unrestricted non-commercial \\ use, distribution, and reproduction in any medium, provided the original work is properly cited.
}

\begin{abstract}
Emerging and reemerging infections are a huge threat to the human race which can destabilize humans from the roots. It is a global problem and not a problem for any single country. 15 million deaths occur annually across the globe due to infections, and $12 \%$ of them are due to emerging pathogens. These infections are returning every year with an increased incidence rate and higher virulence. In the present era of globalization and living conditions, such as living in crowded areas increases the potential for the spread of these emerging and reemerging infections, eventually affecting public health. The most prominent challenge that poses in the face of public health officials is the achievement of global preparedness to combat these infections. Aggressive research is needed in this field to help being prepared for an attack by these infections. Global organizational cooperation, international research funding, and poverty reduction are very much necessary for taking measures against these infections.
\end{abstract}

Keywords: Emerging infections, Public health, Research, Re-emerging infections

\section{INTRODUCTION}

Emerging diseases came into the limelight during the late 1960s-1970s when the viral hemorrhagic fevers made their first appearance in humans. ${ }^{1}$ These are diseases whose incidence rates have increased in humans in the past two decades and pose a severe threat to grow in the future. ${ }^{2} 15$ million deaths occur annually across the globe due to infections, and $12 \%$ of them are due to emerging pathogens. ${ }^{3}$ Emerging infectious diseases are further divided as newly emerging wherein these diseases have been discovered in humans, or a population which have never occurred till date and reemerging infections wherein diseases reappear in a more virulent form with an increased incidence rate or in a geographically new location after the disease has been eradicated from that territory or place. ${ }^{4}$ Emerging infectious diseases have been a severe threat to humans which demands increased awareness and preparedness at a global level to combat these diseases. There have been 35 new pathogens that have been identified in the past four decades. ${ }^{5}$ This paper reviews the burden, challenges faced, achievements in this field, and future recommendations to combat these diseases.

\section{CAUSES OF EMERGING INFECTIOUS DISEASES}

Centers for Disease Control and Prevention (CDC) has enumerated many factors for the emergence and reemergence of these new infections. Firstly, genetic causes such as genetic mutation, recombination occurring in nucleic acid structures of the microbes leading to increased virulence and adaptability to hostile environments and drugs. Secondly, environmental factors such as deforestation, urbanization have led to changes in ecological settings of the microbes and further increased their virulence to infect humans. Thirdly, sociodemographic factors such as population increase, the density of population and lower living standards and social insecurity also are paving the path for the microbes. Lastly, the deliberate introduction of pathogens which have been 
eradicated by a human action for use as biological weapons also poses a severe threat to the human race. ${ }^{1}$

\section{MODES OF SPREAD}

A total $60 \%$ of EIs are transmitted zoonotically, $5-10 \%$ is transmitted through the environment and remainder are spread by human to human cycle. ${ }^{6}$ The emerging and reemerging infectious diseases follow the same pathway of transmission as any other contagious disease. They start with the reservoir which uses a vector to transmit the microorganisms to host such as a human. Behavioral and political factors are collectively responsible for the spread of an outbreak and therefore should be given priority to concentrate on during an outbreak. ${ }^{7}$ The transmission of emerging and reemerging infections can be affected by living habits of a specific population. ${ }^{8}$

\section{THREAT OF EMERGING AND REEMERGING INFECTIONS IN THE CURRENT WORLD}

The World Health Organization (WHO) on December 8-9, 2015 proposed to develop a process to prioritize the most critical emerging and reemerging infections with epidemic or pandemic potential in consultation with scientists and public health experts in Geneva. Seven diseases have been declared by WHO as the most critical emerging and reemerging infections of highest risk and they are Crimean-Congo hemorrhagic fever, Filovirus diseases (Ebola virus disease and Marburg), highly pathogenic emerging Coronaviruses relevant to humans (MERS Co-V and SARS), lassa fever, nipah, rift valley fever, and a "new disease". This "new" disease is named for any new unknown illness that would emerge in the future and may require immediate containment actions to prevent an outbreak. ${ }^{1}$ Apart from these seven diseases, the WHO listed three other conditions, namely, Chikungunya, severe fever with thrombocytopenia syndrome and Zika. Chikungunya is one of the most prevalent conditions with varied types of clinical presentations and affecting many tropical and sub-tropical countries. ${ }^{9}$ Aeromonas species, another emerging pathogen infecting humans through consumption of contaminated food has been on the rise in the Middle East since 2015. ${ }^{10}$

\section{IMPORTANCE OF PUBLIC HEALTH}

Public health expertise is the mainstay to tackle these emerging and reemerging infections. ${ }^{11}$ Public health measures focus on eliminating the factors responsible for the emergence and transmission of these diseases and implementing control measures to curtail the spread of these infections. Advocacy, awareness, research studies, vaccinations are the most critical public health measures to restrict the spread of these infections. International travel measures, provision of personal protective measures are other public health measures to stop the spread of these diseases and prevent an epidemic/pandemic. ${ }^{12}$ The 'Special Pathogens Branch' at the CDC powered by WHO is responsible for research activities towards understanding these emerging pathogens and diseases which would help control these EIs. ${ }^{1}$ Emerging Infectious Disease Program (EIP) data is used for public health policies recommendations and to measure the effectiveness of existing programs. ${ }^{13}$ Activities performed by EIP network are active bacterial core surveillance (ABCs), food net, influenza activities and healthcare-associated infectionscommunity interface (HAIC) projects. $^{14}$ Global organizational cooperation, international research funding, and poverty reduction are very much necessary towards taking measures against these infections. ${ }^{15}$

\section{ADVANCEMENTS IN MEASURES OF CONTROL}

The new drugs which are being developed against these infections make use of assay development, high throughput screening hit confirmation, lead identification and development, animal model evaluation, toxicity studies, regulatory issues, generic drug discovering and development infrastructure. ${ }^{16}$ DNA vaccine for zika virus is on a clinical trial, which is the most significant advancement presently achieved concerning emerging zika infection. ${ }^{17}$ Tremendous advances at the molecular level of genetics have helped in identification of these new and dangerous emerging and reemerging pathogens. ${ }^{1}$ The usage of virus-like particles in vaccines for preventing these infections is under trial as opposed to the cellcultured based vaccines. ${ }^{18}$ The above research studies are always associated with potential risks of misuse but must be continued to tackle these infections. These studies are called dual-use research of concern. ${ }^{19}$ Emerging infection programs (EIP) have contributed a lot towards improving the social determinants of disease and thereby keeping a check on these diseases. ${ }^{20}$ There are many modalities of advancements regarding laboratory tests which make use of nucleic acid amplification, antigen and antibody testing extensively by the laboratories. ${ }^{15}$

\section{CHALLENGES AHEAD}

Despite the above advances in the field of science, people are dying due to these emerging and reemerging infections due to the emergence of new pathogens with increased virulence. Communicating recent studies and their data in the background of uncertainty is very challenging for public health professionals but must be done. ${ }^{21}$ Genetic variation in the microbes, antimicrobial resistance are some challenges faced in controlling these infections. Surveillance for these diseases is the most crucial step required for effective control of these infections as monitoring helps to have adequate preparedness programs to combat these infections as was in the case of LGV outbreak in London in 2003. ${ }^{22}$ These surveillance programs must also include animals and risk factors to get to the roots of these new emerging infections and thereby prevent their emergence and also to take measures to control them. ${ }^{23}$ Various challenges faced by the laboratories in the diagnosis of these diseases such as assay validation, standardization of protocols, reagent shortages and standardized materials among multiple countries could 
be overcome by the establishment of regional and global lab networks under the guidance of WHO. ${ }^{15}$ The only ways to control the spread of these emerging infections are through increased international cooperation, efficient local, regional and global surveillance programs and exchange of scientific advancements against these microbes.

\section{CONCLUSION}

Emerging and re-emerging infections are a huge threat to the human race which can destabilize humans from the roots. It is a global problem and not a problem for any single country. Public health expertise is the mainstay to tackle these emerging and re-emerging infections. The most significant challenge that poses in front of public health officials is the achievement of global preparedness to combat these infections. Aggressive research is needed in this field to help being prepared for an attack by these infections. Global organizational cooperation, international research funding, and poverty reduction are very much necessary for taking measures against these infections.

Funding: No funding sources

Conflict of interest: None declared

Ethical approval: Not required

\section{REFERENCES}

1. Nii-Trebi NI. Emerging and Neglected Infectious Diseases: Insights, Advances, and Challenges. BioMed Res Inter. 2017;2017:15.

2. Beigi RH. Emerging infectious diseases in pregnancy. Obstet Gynecol. 2017;129(5):896-906.

3. Dye C. After 2015: infectious diseases in a new era of health and development. Philos Trans R Soc Lond B Biol Sci. 2014;369(1645):20130426.

4. Morens DM, Fauci AS. Emerging infectious diseases: threats to human health and global stability. PLOS Pathogens. 2013;9(7):e1003467.

5. Bhatia R. Emerging challenges and opportunities in medical microbiology. Indian J Med Microbiol. 2017;35(1):4-7.

6. van Doorn HR. Emerging infectious diseases. Medicine (Abingdon). 2014;42(1):60-3.

7. Walker NF, Whitty CJ. Tackling emerging infections: clinical and public health lessons from the West African Ebola virus disease outbreak, 20142015. Clin Med (Lond). 2015;15(5):457-60.

8. Holmberg M. Public health and infections: Health in Sweden: The National Public Health Report 2012. Chapter 15. Scandinavian J Pub Health. 2012;40(9suppl):275-80.

9. Rahim MA, Uddin KN. Chikungunya: an emerging viral infection with varied clinical presentations in
Bangladesh: Reports of seven cases. BMC Res Notes. 2017;10(1):410-0.

10. Alhazmi MI. Isolation of Aeromonas spp. from Food Products: Emerging Aeromonas Infections and Their Significance in Public Health. J AOAC Int. 2015(4):927.

11. McFee RB. Selected epidemics and emerging pathogens. Disease-a-Month. 2017;63(9):240-6.

12. Nguyen-Van-Tam JS, Sellwood C. Intervention strategies for emerging respiratory virus infections: policy and public health considerations. Current Opin Virol. 2013;3(2):192-8.

13. Lynfield R, Schaffner W. Emerging Infections Program--20 Years of Achievements and Future Prospects. Emerg Infect Dis. 2015;21(9):1497-8.

14. Centers for Disease Control and Prevention (CDC). Emerging infections programs. 2017. Available at: https://www.cdc.gov/ncezid/dpei/eip/index.html. Accessed on 8th June 2017.

15. Chan JFW, Sridhar S, Yip CCY, Lau SKP, Woo PCY. The role of laboratory diagnostics in emerging viral infections: the example of the Middle East respiratory syndrome epidemic. J Microbiol. 2017;55(3):172-82.

16. Everts M, Cihlar T, Bostwick JR, Whitley RJ. Accelerating drug development: antiviral therapies for emerging viruses as a model. Ann Review Pharmacol Toxicol. 2017;57(1):155-69.

17. Morrison C. DNA vaccines against Zika virus speed into clinical trials. Nature Reviews Drug Discover. 2016;15(8):521-2.

18. Jeong H, Seong BL. Exploiting virus-like particles as innovative vaccines against emerging viral infections. J Microbiol. 2017;55(3):220-30.

19. Lev O, Rager-Zisman B. Protecting public health in the age of emerging infections. IMAJ -RAMAT GAN. 2014;16(11):677-82.

20. Hadler JL, Vugia, D, Bennett NM, Moore MR. Emerging infections program efforts to address health equity. Emerg Infect Dis. 2015;21(9):1589-94.

21. Bell BP, Boyle CA, Petersen LR. Preventing zika virus infections in pregnant women: an urgent public health priority. Am J Public Health. 2016;106(4):589-90.

22. Rönn M, Hughes G, Simms I. Challenges presented by re-emerging sexually transmitted infections: an observational study of lymphogranuloma venereum in the UK. The Lancet. 2013:382-S86.

23. Banerjee A. Zika virus: another call for paradigm shift in disease control strategy. Med J Dr DY Patil University. 2016;9:288.

Cite this article as: Veerapalli $\mathrm{H}$. Emerging and reemerging infections: threat to the World. Int J Community Med Public Health 2020;7:788-90. 